\title{
Libros y revistas recibidas
}

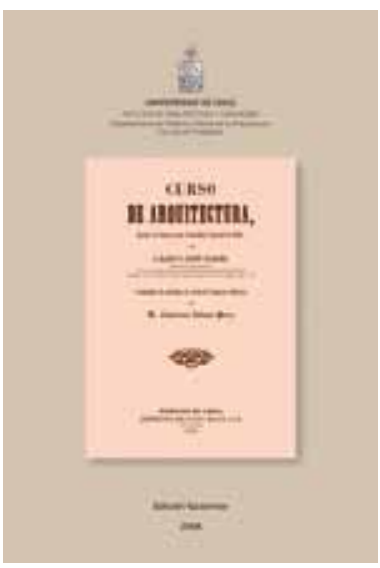

Curso de Arquitectura. Claude F. Brunet de Baines. Edición facsimilar. Departamento de Historia y Teoría de la Arquitectura + Escuela de Posgrado, FAU, Universidad de Chile Libro que reedita el "Curso de Arquitectura» publicado por el arquitecto francés Claude F. Brunet de Baines en el año 1853, dando cuenta de los primeros antecedentes de sistematización de la enseñanza de la arquitectura en nuestro país. Se trata también del primer tratado editado en América durante el siglo xIx. Un libro fundamental para comprende los antecedentes del proceso de enseñanza de la disciplina en Chile y América.

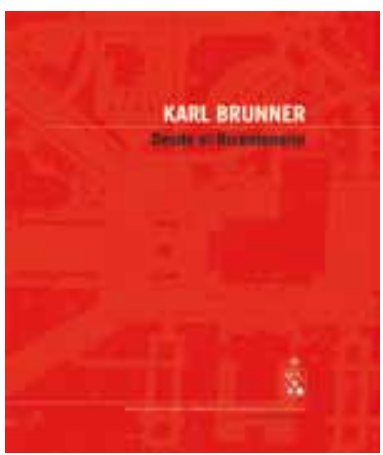

Karl Brunner. Desde el Bicentenario. Revista De Arquitectura +

Departamento de Urbanismo, FAU, Universidad de Chile, en colaboración con la Embajada de Austria

La figura del arquitecto urbanista austríaco Karl Brunner es la temática central de esta publicación. Una revisión a la importante obra de Brunner en nuestro país, que junto con abordar retrospectivamente su obra, analiza los alcances que aún hoy tiene su obra en el desarrollo urbano de nuestro país.

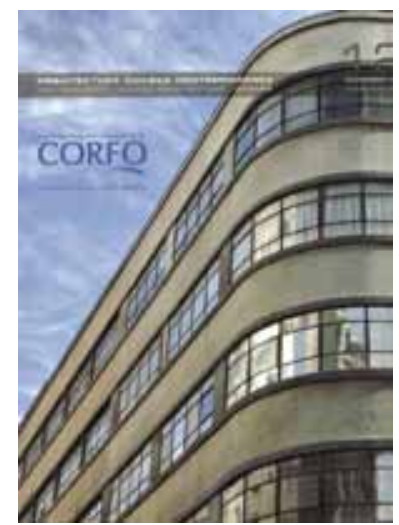

Revista Aoa N ${ }^{\circ} 12$, diciembre 2009. Asociación de Oficinas de Arquitectos

Revista chilena de arquitectura contemporánea perteneciente a la Asociación de Oficinas de arquitectos. En la presente edición se puede encontrar un interesante artículo sobre el arquitecto Sergio Larraín Gracia Moreno, el resultado del Concurso de recuperación del Edificio Emilio Pugin de la Facultad de Ciencias de la Universidad Austral y un recorrido por obras de arquitecturas recientes en Chile.

Arquitectura del Paisaje. Casos de análisis e investigación efectuados

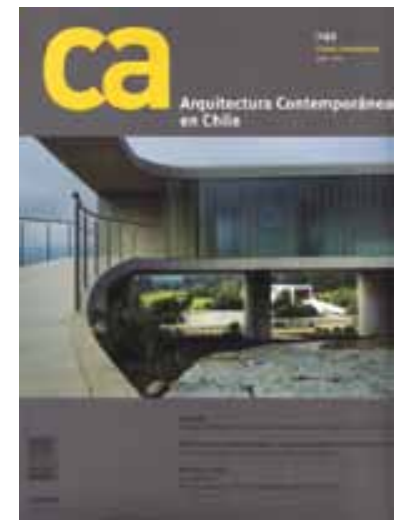

Revista ca $\mathrm{N}^{\circ} 143$, diciembre

2009 - enero 2010. Arquitectura

Contemporánea en Chile. Colegio de Arquitectos de Chile

Una revisión del estado de la arquitectura contemporánea chilena y su vinculación con la tradición moderna desarrollada durante el siglo xx, constituyen los temas centrales de la última edición de revista ca. En la sección obras se presenta una amplia revisión a la Casa White $O$ realizada por Toyo Ito en nuestro país.

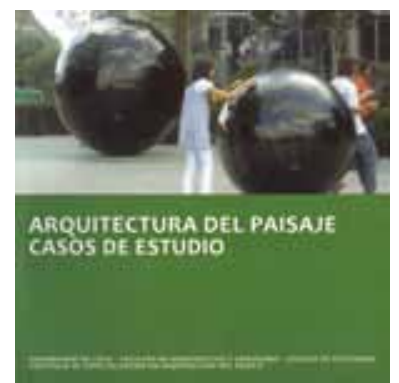
Estudio. Postítulo de Especialización en Arquitectura del Paisaje, Escuela de Posgrado, FAU, Universidad de Chile

Una publicación que reúne interesantes experiencias de en el marco del postítulo de especialización en arquitectura del paisaje de la Universidad de Chile. El vínculo entre arte y paisaje, los instrumentos de planificación territorial o la problemáticas

asociadas al transporte público, son algunas de las temáticas abordadas por este libro.

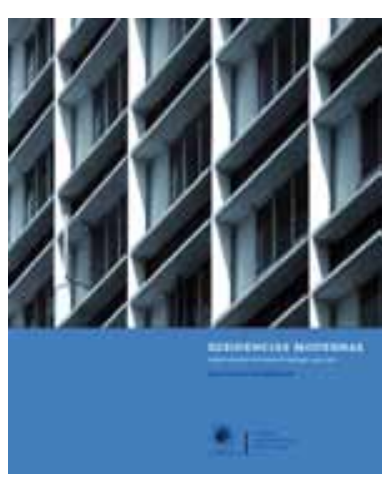

Residencias Modernas. Habitar colectivo en el centro de Santiago, 1930-1970. Andrés Téllez T. + Cristóbal Molina B. Facultad de Arquitectura Arte y Diseño UDP, Ediciones Universidad Diego Portales

Un repaso analítico por algunos de los más significativos proyectos de vivienda colectiva desarrollados en Santiago durante el siglo anterior. Diseñadas bajo el paradigma de la modernidad, las obras escogidas nos permiten aproximarnos a los modos de habitar pensados arquitectónicamente entre las década del '30 y los '70. Planos y cuidadas imágenes acompañan estudio.

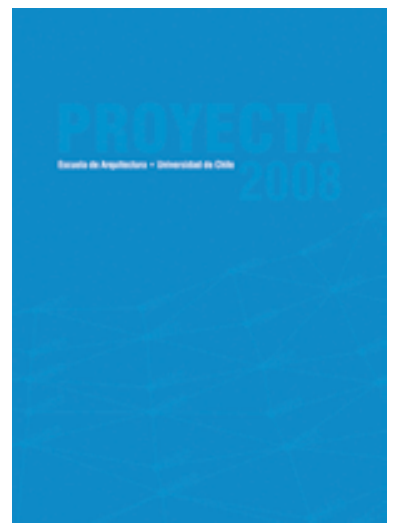

Anuario de Arquitectura Proyecta 2008. Facultad de Arquitectura y Urbanismo, Universidad de Chile Publicación que recoge y recopila los más destacados trabajos realizados por los estudiantes de la Escuela de Arquitectura de la Universidad de Chile. En esta ocasión, no sólo se tendrá acceso a los mejores proyectos de los diferentes talleres y cursos vinculados al diseño arquitectónico, sino también a los Seminarios de Investigación de $5^{\text {to }}$ año y a una selección de Proyectos de Título.

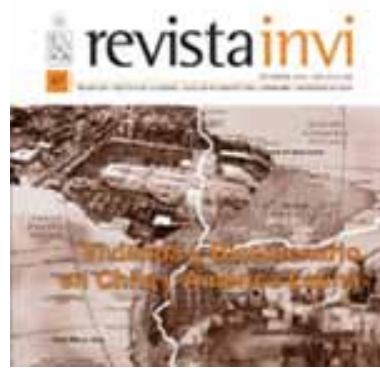

Revista INVI N 67, noviembre 2009. Vivienda Bicentenario en Chile y América Latina Instituto de Ia Vivienda, FAU, Universidad de Chile Próximos al Bicentenario, la revista INVI aprovecha la oportunidad para repensar las políticas de vivienda interesante recuento del desarrollo de viviendas sociales en países latinoamericanos. en Chile, junto con hacer un

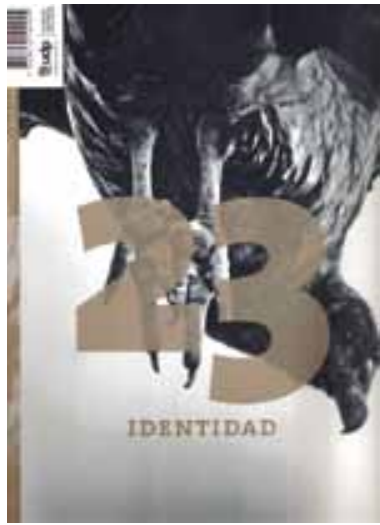

Revista $180 \mathrm{~N}^{\circ} 23$, Identidad, agosto 2009. Facultad de Arte y Diseño, Universidad Diego Portales La identidad y sus alcances, es la problemática abordada por la última edición de revista 180 de la Universidad Diego Portales. Los retratos fotográficos como registro de identidad, las fiestas urbanas y su presencia dentro de la ciudad, las referencias históricas y religiosas como enlaces de memoria, son algunas de las temáticas que podemos encontrar en este número.

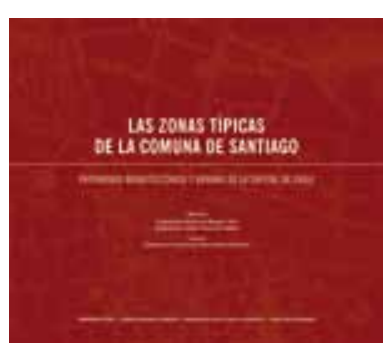

La Zonas Típicas de la Comuna de Santiago. Patrimonio arquitectónico y urbano de la Capital de Chile.

Patricio Basáez $\mathrm{Y}$ + Jaime Daroch $\mathrm{N}$. Coautor: Constantino Mawromatis $\mathrm{P}$. Departamento de Historia y Teoría de la Arquitectura + Departamento de Urbanismo, FAU, Universidad de Chile

Completo y detallado análisis de

las zonas típicas de la ciudad de Santiago. Acompañado de imágenes y planos de alta calidad esta edición se convierte en un material de consulta obligado para valorar el desarrollo arquitectónico de la capital de Chile y la conformación de la identidad de la ciudad. 